\title{
Reflexivity in English, French and Kinshasa Lingala: Similarities and Differences
}

\author{
Larice Toko Lumanda \\ Department of English Letters and Civilization, University of Kinshasa, Kinshasa, Democratic Republic of Congo
}

Email address:

lumanda08@gmail.com

To cite this article:

Larice Toko Lumanda. Reflexivity in English, French and Kinshasa Lingala: Similarities and Differences. Communication and Linguistics Studies. Vol. 5, No. 1, 2019, pp. 1-7. doi: 10.11648/j.cls.20190501.11

Received: March 15, 2019; Accepted: April 22, 2019; Published: May 15, 2019

\begin{abstract}
Dunker [15] asserts that "linguistic reflexivity is a feature of the communication process, and it essentially depends on situated participants and time. It is a defining characteristic of the human language but despite its obvious importance, it is not very well understood theoretically, and it is strangely under-researched empirically". Reflexivity exists in English, French, and Kinshasa Lingala. In all these languages, reflexivity is expressed by reflexive pronouns, reciprocal pronouns, reflexive verbs, and ergative verbs. The position and use of these pronouns and verbs differ from one language to another. Therefore, this article attempts to examine reflexivity in each of these languages in order to point out similarities and differences. The focus is on the use of reflexive pronouns, reciprocal pronouns, reflexive verbs, and ergative verbs in English, French, and Kinshasa Lingala. This article is based on observation, interview, and contrastive analysis which allows to sort out similarities and differences between languages. Observation was used during people's talk on buses, at markets, on radios, and in avenues. An interview was prepared for some people in the Kinshasa community especially teachers. The results show that English, French, and Kinshasa Lingala use pronouns to express reflexivity. Reflexivity is expressed through the use of reflexive pronouns which have different positions in these three languages. In English, they occur in the object position. In French, they occur after a personal pronoun subject and before the verb. In Kinshasa Lingala, they occur in the verbal prefix position. As far as reciprocal pronouns are concerned, in English a reciprocal pronoun is used without reflexive pronoun whereas in French, reciprocal pronoun is optional and it is used with reflexive pronoun. In Kinshasa Lingala, the reciprocal pronoun is suffixed to the verb. It is a bound morpheme. Reflexivity is expressed by ergative verbs in English, French, and Kinshasa Lingala. In English, no reflexive pronoun is used with ergative verbs. In French, ergative verb is used with a reflexive pronoun "se". In Kinshasa Lingala, the ergativity is expressed by the bound morpheme -ma or -mi. In conclusion, the similarities are at the level of the use of reflexive pronouns, reciprocal pronouns, and ergative verbs. Whereas the differences appear in the position occupied by the reflexive components. In English, reflexive pronouns and reciprocal pronouns occur in the object position. In French, they occur between the subject and the verb. In Kinshasa Lingala, the reflexive pronoun occurs in the verbal prefix position. Reciprocal pronoun occurs in the suffix position. Ergativity is expressed by -ma/-mi in the suffix position.
\end{abstract}

Keywords: Reflexivity, Reflexive Pronouns, Reciprocal Pronouns, Reflexive Verbs, and Ergative Verbs

\section{Introduction}

The way reflexivity is expressed in English, French, and Kinshasa Lingala requires a special attention since in these languages, reflexive components (reflexive pronouns, reciprocal pronouns, reflexive verbs, and ergative verbs) present different positions and uses.

The aim of this article is to contrast reflexivity in English, French, and Kinshasa Lingala in order to point out the similarities and differences. This paper is written on the basis of observation, interview, and contrastive analysis. Observation was used during people's talk on buses, at markets, on radios, and in avenues. An interview was prepared for some people in the Kinshasa community especially teachers.

There are four main sections in this article. The first one deals with reflexivity in English. It focuses on reflexive pronouns, reciprocal pronouns, and ergative verbs. The 
second section is devoted to reflexivity in French. It discusses the French reflexive pronouns, reciprocal pronouns, and reflexive verbs known as "verbes pronominaux". The third part explains reflexivity in Kinshasa Lingala. The main concern here is to show that in Kinshasa Lingala, there is one reflexive pronoun for all the persons (mi-) which is a bound morpheme, reciprocal pronoun (-na) which is also a bound morpheme, and (-ma/-mi) that expresses the ergativity of verbs. The last section contrasts the sentences expressing the same ideas in English, French, and Kinshasa Lingala in order to point out similarities and differences.

\section{Definition}

According to https://en.m.wikipedia.org/wiki/reflexivity(grammar) [4] "in grammar, reflexivity is a property of syntactic constructs whereby two arguments (actual or implicit) of an action or relation expressed by a single predicate have the same reference". Reflexivity is the fact that the action performed by the subject is reflected on the same subject. Reflexivity is expressed through the use of reflexive pronouns, ergative verbs, reflexive verbs (in French), verbal prefix (in Lingala). In the following section, the focus is on reflexivity in the English language.

\section{Reflexivity in English}

In the English language, reflexivity is expressed either by reflexive pronouns, reciprocal pronouns, or by ergative verbs. Let us have a look at each of them.

\subsection{Reflexive Pronouns}

https://en.oxforddictionaries.com/definition/reflexive [5] defines the adjective reflexive as "denoting a pronoun that refers back to the subject of the clause in which it is used". Reinhart and Reuland [10] writes that "in English language, specially, a reflexive pronoun will end in -self or -seves, and refers to a previously named noun or pronoun (myself, yourself, ourselves, etc)". For O'Grady [9], reflexive pronouns 'introduce a 'referential dependency', which the processor must resolve by finding an appropriate referent". According to https://www.grammarly.com [8] "reflexive pronouns are words ending in -self or selves that are used when the subject and object of a sentence are the same" (online January 29 , 2019 20:32). Ducarpe [13] adds "a reflexive pronoun is used as an object when the subject of a sentence and its object are the same person or thing". Reflexive pronouns are also called anaphors. Gardelle [1] argues that "the term 'anaphor' only applies to some reflexives and to reciprocal pronouns". Reflexive pronouns must agree with nouns (antecedents) and personal pronouns. Antecedent being understood as noun assigning meaning to pronouns as it is written in https://en.m.wikipedia.org/wiki/antecedent_grammar [2] that "in grammar, an antecedent is an expression (word, phrase, clause, sentence, etc) that gives it meaning to a proform (pronoun, pro-verb, pro-adverb, etc)" (Online: January $29^{\text {th }}$, 2019 20:36).

(1) $[\text { John }]_{\mathrm{i}}$ washes $[\text { himself }]_{\mathrm{i}}$

(2) $[\mathrm{He}]_{\mathrm{i}}$ washes $[\text { himself }]_{\mathrm{i}}$.

(3) $[\text { Jane }]_{\mathrm{i}}$ washes $[\text { herself }]_{\mathrm{i}}$.

(4) $[\text { She }]_{\mathrm{i}}$ washes $[\text { herself }]_{\mathrm{i}}$

In (1) the reflexive pronoun 'himself' agrees with the antecedent (John) in gender (masculine), number (singular), and person ( $3^{\text {rd }}$ person). If the reflexive pronoun does not agree with the antecedent or pronoun in gender, number, and person the sentence or utterance becomes ungrammatical.

(5) *John washes herself

The sentence (5) is ungrammatical because the reflexive pronoun 'herself' does not agree with the antecedent 'John' in gender, 'John' is masculine whereas 'herself' is feminine. This is why there must be an agreement in gender, number, and person between personal pronoun subjects.
a. "I" agrees with "myself"
b. "You" agrees with "yourself"
c. "He" agrees with "himself"
d. "She" agrees with "herself"
e. "It" agrees with "itself"
f. "We" agrees with "ourselves"
g. "You" agrees with "yourselves"
h. "They" agrees with "themselves"

The examples below illustrate each case:

(6) I wash myself.

(7) You wash yourself.

(8) He washes himself.

(9) She washes himself.

(10) It washes itself.

(11) We wash ourselves.

(12) You wash yourselves.

(13) They wash themselves.

The third person pronouns subject (he, she, it, and they) can be replaced by nouns (antecedents) as in (8) the personal pronoun subject 'he' can be replaced by 'john'. In (9), the personal pronoun subject 'she' can be replaced by 'Mary'. In (10), the personal pronoun subject 'it' can be replaced by 'the duck'. In (13), the personal pronoun subject 'they' can be replaced by 'John and Mary'.

The reflexive pronouns 'myself, yourself, and yourselves' are used with personal pronouns subjects, but they are not used with nouns (antecedents). For example in (6), 'I' cannot be replaced by a noun. If it is replaced by a noun, the sentence or utterance becomes ungrammatical as in

(14) *Etienne wash myself.

In (7), 'you' cannot be replaced by 'Smith' as in

(15) *Smith wash himself.

In (11), 'we' cannot be replaced by 'Smith and Paul' as in

(16) Smith and Paul wash ourselves.

In (12), 'you' cannot be replaced by 'Jack and James' as in (17) Jack and James wash yourselves.

The second person reflexive pronouns (yourself and yourselves) are grammatically used in the imperative forms.

(18) Wash yourself.

(19) Wash yourselves. 
In (18) and (19), the reflexivity does not indicate that the action is reflected on the order-giver (i.e. the person giving the order). The action is reflected on the order-receiver (i.e. the person receiving the order). The order-receiver is the doer of the action which is reflected on him/her (=the doer). Let us call this reflexivity a 'further reflexivity' because the reflexivity is not accomplished yet. Furthermore, Ejomafuvwe and Okenrentie [16] affirm that "in the grammar of a language, the reflexive verb is part of the structure of speech which shows the action of the verb being executed on the speaker while the action of other verbs is received by other objects outside the speaker"

Reflexive pronouns occur in the object position i.e. after the verb in agreement with the gender, number and person. It should be pointed out that reflexive pronouns do not occur after all verbs.

There are verbs after which reflexive pronouns are used and verbs which do not allow the use of reflexive pronouns after them. Here are some of the verbs after which reflexive pronouns are used.
a. Wash
b. See
c. Cut
d. Protect
e. Kill
f. Judge
g. Feed
h. Care (about)
i. Ask
j. Etc.

There are other verbs that do not allow the use of reflexive pronouns after them unless these pronouns express the aloneness with emphasis instead of reflexivity. Some of these verbs are
a. Walk
b. Go
c. Eat
d. Do
e. Drink
f. Read
g. Work
h. Cook
i. Watch
j. Play
k. Etc.

For example, in the sentence (20) below, the reflexive pronoun does not express reflexivity. It simply shows that Mary does her homework without any help from someone else.

(20) Mary does her homework herself.

For a reflexive pronoun to express reflexivity, it must follow a verb that reflects the action on the doer of the action as in the example bellow.

(21) Mary feeds herself.

In (21), the action of feeding is reflected on Mary who is the doer of the action.

\subsection{Reciprocal Pronouns}

Reciprocal pronouns (one another, each other, etc) indicate that the same action is performed by two or more doers and the action of their performance is reflected on each other. In https://www.gingersoftware.com [7], a reciprocal pronoun is defined as "a pronoun which is used to indicate that two or more people are carrying out or have carried out an action of some type, with both receiving the benefits or consequences of that action simultaneously". Online: January $29^{\text {th }}, 2019$ 20:40.

(22) John and Peter greet each other.

In (22), John is the doer of the action 'greeting' towards Peter. Peter is also the doer of the same action towards John. Therefore, the action 'greeting' is reflected on both of them (John and Peter). This fact is also a reflexivity because the action is reflected on its doers.

As reflexive pronouns occur in the object position, the reciprocal pronouns also occur in the object position. They do not occur after all verbs. They occur only after verbs that allow the reciprocity. Here are some of the verbs that allow the reciprocity.
a. Greet
b. Call
c. Visit
d. Love
e. Hate
f. Know
g. Insult
h. Wash
i. Beat
j. Help
k. Etc.

Some other verbs do not allow the use of reciprocal pronouns after them. This is the case of the verbs
a. go
b. sleep
c. play
d. walk
e. travel
f. write
g. fall
h. feel
i. swim
j. smoke
k. etc.

In some cases, the verbs can be used with reciprocal pronouns when prepositions and genitive case or genitive case only are used. Let us consider the examples below:

(23) John and Peter go to each other's house.

(24) We sleep on each other's bed.

(25) The kids play with each other's toys.

(26) They walk on each other's mat.

(27) The business men travel by each other's cars.

(28) We swim in each other's swimming pool.

(29) They fall in each other's trap.

(30) We write with each other's pen. 
(31) They smoke each other's cigarette.

One can notice that reciprocal pronouns are not used with the first, second, and third persons singular because reciprocity can be effective only when there are two or more doers.

Reciprocity can also be expressed by certain verbs without the use of reciprocal pronouns. Some of the verbs are (fight, quarrel, etc).

(32) John and Peter fight.

In (32), the reciprocity is expressed by the verb ' $f i g h t$ ' although a reciprocal pronoun is not used. The verb 'fight' presupposes more than one doer of the action. Fighting implies people beating each other.

\subsection{Ergative Verbs}

Ergative verbs are verbs used in an intransitive way. They make the agent behave as the subject of the verb as it is written in (https://en.m.wikipedia.org/wiki/ergative verb [3] online: January 29th, 2019 at 20:49) and Richards, J. \& Schmidt, R. [12] "in Linguistics, an ergative verb is a verb that can be either transitive or intransitive, and whose subject when intransitive corresponds to its direct object when transitive"

(33) The glass broke.

(34) The water boils.s

(35) The window closed.

(36) The ice cream is melting.

(37) This rice cooks easily.

In (33), 'the glass' is the subject of the verb 'broke'. The action of breaking is reflected on the subject although no reflexive pronoun is used. It is the glass which was broken, but it appears as the doer of the action. This is the same case with the examples (34), (35), (36), and (37). All these sentences can be well explained, if they are rewritten in both active and passive forms.

(38) Thomas broke the glass. (Active form)

(39) The glass was broken by Thomas. (passive form)

In (38), Thomas is the doer of the action (breaking) whereas the glass is the object. In this case, there is no reflexivity. In (39), Thomas becomes agent, and the glass becomes patient. Again here there is no reflexivity. As Storoshenko [11] states that " $a$ voice usually found in ergative languages, in which a transitive verb becomes intransitive, its subject being changed from the ergative/agentive case to be absolutive/patientive case". In (39) the glass is both the doer and the patient. That is to say the action is reflected on the doer. The ergative verbs express reflexivity in the English language.

\section{Reflexivity in French}

In the French language, reflexivity is expressed through reflexive pronouns (conjunctive and disjunctive forms) which are used together with personal pronouns subjects and reflexive verbs.

\subsection{French Reflexive Pronouns}

French reflexive pronouns are classified into "pronoms réfléchis forme conjointe" (reflexive pronouns conjunctive form) and "pronoms réfléchis forme disjointe" (reflexive pronouns disconjunctive form). https://français.lingolia.com [6] defines pronom réfléchi in this way "les pronoms réfléchis sont me, te, se, nous, vous. Ils sont employés avec les verbes pronominaux. Ils se réfèrent toujours au sujet et sont de la même personne que celui-ci". (Reflexive pronouns are me, te, se, nous, vous. They are used with reflexive verbs).

\subsubsection{Pronoms Réfléchis Forme Conjointe}

Pronoms réfléchis forme conjointe are reflexive pronouns that are placed before certain French verbs in order to reflect the action on the subject. The following are the pronoms réfléchis forme conjointe.

"Me" or " $\mathrm{m}$ " ": the first person singular

"Te" or " $t$ ",: the second person singular

"Se" or " $s$ "”: third person singular

"Nous": first person plural

"Vous": second person plural

"Se": third person plural.

French reflexive pronouns have a syntactic relationship of agreement with personal pronouns subjects namely je, $t u, i l$, elle, nous, vous, ils, elles. To express reflexivity, personal pronouns subjects must agree with reflexive pronouns with regards to person, gender, and number.

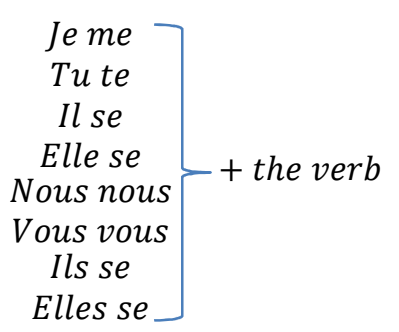

If this order is not respected, reflexivity is not expressed. The following examples illustrate reflexivity when the order is respected and non-reflexivity when the order is not respected.

(40) Je me lave

(41) Je te lave

In (40), there is reflexivity because $j e$ and $m e$ are the same person on which the action is reflected. In (41), there is no reflexivity because je and te are not the same person. Je is the first person singular whereas te is the second person singular. Therefore, there is no reflexivity because the action is not reflected.

\subsubsection{Pronoms Réfléchis Forme Disjointe}

There are two types of pronoms réfléchis forme disjointe. The first form is called pronoms réfléchis forme disjointe simple (moi, toi, lui, elle, nous, vous, eux) which are linked to certain verbs by means of an hyphen in imperative form. The second form is pronoms réfléchis forme disjointe longue (moi-même, toi-même, lui-même, elle-même, nous-mêmes, vous-mêmes, and eux-même). Another pronom réfléchi forme disjointe is soi-même. This one is neuter. 


\subsection{Verbes Pronominaux}

"Verbes pronominaux" are verbs that are always preceded by a reflexive pronoun. These verbs are classified in pronominaux réfléchis, pronominaux réciproques, verbes pronominaux à sens passif, and verbes essentiellement pronominaux.

\subsubsection{Pronominaux Réfléchis}

The pronominaux réfléchis are verbs that are used for both reflexivity and non-reflexivity. That is, they express reflexivity when they are used with reflexive pronouns. They express non-reflexivity when they are not used with reflexive pronouns.

(42) Marie se lave. (Mary washes herself.)

(43) Marie lave son bébé. (Mary washes her baby.)

In (42), the verb "se laver" is a reflexive verb because it is used with the reflexive pronoun "se". Whereas in (43), the verb "laver" is not a reflexive verb because it is not preceded by "se", and the action is not reflected.

\subsubsection{Pronominaux Réciproques}

These are verbs which express reciprocity by being preceded by a reflexive pronoun.

(44) Les scouts se saluent (l'un l'autre) avec les mains gauches. (Scouts greet each other with left hands.)

In (44), the use of "se" with the verb "saluer" indicates that the action of "greeting" is reciprocal between the scouts.

\subsubsection{Verbes Pronominaux à Sens Passif}

This type of French verbs is like the ergative verbs in English. They are transitive verbs which are changed into intransitive verbs by using ' $s e$ ' before them.

(45) Le maïs se vend au marché. (corn sells at market.)

\subsubsection{Verbes Essentiellement Pronominaux}

Verbes essentiellement pronominaux are French verbs which are used exclusively with reflexive pronouns. Here below are some of the verbes essentiellement pronominaux.

a. S'adonner: give oneself up

b. Se dédire: retract

c. Se désister: withdraw

d. S'évanouir: faint

e. S'évader: escape

f. S'enfuir: flee

g. S'enrôler: enrol

h. Se lamenter: wail

i. Se méfier de: distrust

Etc.

\section{Reflexivity in Kinshasa Lingala}

Reflexivity in Kinshasa Lingala is expressed through the reflexive pronoun ( $m i-)$, reciprocal pronoun $(-n a),(-m a /-m i)$, and the French reflexive pronoun "se".

\section{1. $m i-$}

$m i$ - is a bound morpheme that occurs in the prefix position to the base of the verb. As Gluckman [14] argues that "like all Narrow Bantu languages, reflexives in Logoori are marked in a preverbal slot". The example below illustrates the case.

(46) Jean a mitali na kitalatala. (John sees himself in the mirror.)

In (46), the reflexive pronoun is $m i$ - which occurs in the prefix position of the verb kotala (see). As one can notice it, the subject of the verb can be constituted by both noun and pronoun. "Jean" is a noun and " $a$ " is personal pronoun subject. In some cases, "ko-" which is an infinitive marker in Lingala is used with $m i$ - to express reflexivity.

(47) Nazo komituna. (I ask myself.)

It is worth pointing out that $m i$ - is used for all the persons, gender, and number. This is illustrated in each of the following examples.

(48) Nazo mitala na kitalatala. (I see myself in the mirror.)

(49) Ozo mitala na kitalatala. (You see yourself in the mirror.)

(50) Azo mitala na kitalatala. (S/he sees herself/himself in the mirror.)

(51) Tozo mitala na kitalatala. (We see ourselves in the mirror.)

(52) Bozo mitala na kitalatala. (You see yourselves in the mirror.)

(53) Bazo mitala na kitalatala. (They see themselves in the mirror.)

\section{2. -na and -ni}

-na and -ni express reciprocity. They are also used for all persons, gender, and number.

(54) To komonana. (We will see each other)

(55) Bo komonana. (You will see each other)

(56) Ba komonana. (They will see each other)

(57) To monani. (We see each other)

(58) Bo monani. (You see each other)

(59) Ba monani. (They see each other)

The difference between $-n a$ and $-n i$ is that $-n a$ is used with verbal prefix " $k o-$ " to mark the future tense and the infinitive of the verbs. This is the case in (54), (55), and (56). Therefore, -na expresses reflexivity in the future. As far as $n i$ is concerned, it expresses reflexivity in the present tense. This is the case in (57), (58), and (59).

\section{3. $-m a$}

- $m a$ expresses an ergative form in Lingala. It is added to the end of verbs as in:

(60) Masangu ezo tekama na wenze. (Corn sells at market.)

In (60), the bound morpheme - ma expresses reflexivity in the sense that it reflects the action on "masangu" (corn) which in fact undergoes the action of being sold.

\subsection{Se}

"se" is a French reflexive pronoun that is used together with verbs to express reflexivity. It is important to notice that 
"se" is used only with third persons (singular and plural) in the French language. In Kinshasa Lingala, "se" is used with all the persons, but not with Lingala verbs. It is used only with French verbs to code switch or code mix. The examples below illustrate the case.

Na se laver naino te. (I have not washed myself yet.)

O se laver naino te. (You have not washed yourself yet.)

A se laver naino te. (S/he has not washed herself/himself yet.)

To se laver naino te. (We have not washed ourselves.)

Bo se laver naino te. (You have not washed yourselves yet.)

Ba se laver naino te. (They have not washed themselves yet.)

\section{Discussion}

The sections above have supplied details about reflexivity in three languages namely English, French, and Kinshasa Lingala. This section contrasts selected sentences that express the same semantic content in English, French, and Kinshasa Lingala in order to pinpoint similarities and differences of reflexivity. The sentences are classified into three groups which express reflexivity. That is the reflexive pronoun group, reciprocal pronouns group, and ergative verbs group.

\subsection{Reflexive Pronouns Group}

Table 1. Positions of Reflexive Pronouns

\begin{tabular}{lll}
\hline English & French & Kinshasa Lingala \\
\hline I see myself in the mirror. & Je me regarde dans le miroir. & Nazo mitala na kitalatala. \\
You see yourself in the mirror. & Tu te regardes dans le miroir. & Ozo mitala na kitalatala. \\
He sees himself in the mirror. & Il se regarde dans le miroir. & Azo mitala na kitalatala. \\
We see ourselves in the mirror. & Nous nous regardons dans le miroir. & Tozo mitala na kitalatala. \\
You see yourselves in the mirror. & Vous vous regardez dans le miroir. & Bozo mitala na kitalatala. \\
They see themselves in the mirror. & Ils se regardent dans le miroir. & Bazo mitala na kitalatala. \\
\hline
\end{tabular}

Reflexivity is expressed through the use of reflexive pronouns which have different positions in these three languages. In English, they occur in the object position. In French, they occur after a personal pronoun subject and before the verb. In Kinshasa Lingala, they occur in the verbal prefix position.

\subsection{Reciprocal Pronouns Group}

Table 2. Reciprocal and Reflexive Pronouns: Relationship

\begin{tabular}{lll}
\hline English & French & Kinshasa Lingala \\
\hline John and Mary greet each other. & Jean et Marie se saluent l'un l'autre. & Jean na Marie bazo mipesa mbote. \\
\hline
\end{tabular}

In English reciprocal pronoun is used without reflexive pronoun whereas in French, reciprocal pronoun is optional and it is used with reflexive pronoun. In Kinshasa Lingala, the reciprocal pronoun is prefixed to the verb. It is a bound morpheme.

\subsection{Ergative Verbs Group}

Table 3. Ergative Verbs and Reflexive Pronouns

\begin{tabular}{lll}
\hline English & French & Kinshasa Lingala \\
\hline The door opens. & La porte s'ouvre. & Porte e fungwami. or Ekuke efunguami \\
\hline
\end{tabular}

Reflexivity is expressed by ergative verbs in English, French, and Kinshasa Lingala. In English, no reflexive pronoun is used with ergative verbs. In French, ergative verb is used with a reflexive pronoun "se". In Kinshasa Lingala, the ergativity is expressed by the bound morpheme - ma or $m i$.

\section{Conclusion}

This article has been examining reflexivity in English, French, and Kinshasa Lingala in order to point out similarities and difference. Firstly, the concept "reflexivity" has been defined as the fact that the action performed by the subject is reflected on the same subject.

Secondly, reflexivity has been examined in English,
French, and Kinshasa Lingala. In English, reflexivity is expressed through reflexive pronouns, reciprocal pronouns, and ergative verbs. In French, reflexivity is expressed through reflexive pronouns and reflexive verbs. In Kinshasa Lingala, reflexivity is expressed through the bound morphemes $m i-$ (equivalent of reflexive pronoun), -na (equivalent of reciprocal pronoun), $-m a /-m i$ (morpheme expressing ergativity), and se which is borrowed from French.

By contrasting sentences having the same semantic content, the fact is that the concept "reflexivity" is expressed in English, French, and Kinsahsa Lingala languages through reflexive pronouns, reciprocal pronouns, and ergative verbs. The differences appear in the position occupied by the reflexive components. In English, reflexive pronouns and 
reciprocal pronouns occur in the object position. In French, they occur between the subject and the verb. In Kinsahsa Lingala, the reflexive pronoun occurs in the verbal prefix position. Reciprocal pronoun occurs in the suffix position. Ergativity is expressed by $-m a /-m i$ in the suffix position.

Similar pieces of work in the comparison of reflexivity in these three languages hardly exist. However, it is advisable that research in this field should be carried out for further findings. For example, Ejomafuvwe and Okenrentie [16] offered a documentation about the comparison between English and Urhobo. Likewise, Gluckman [14] examined reflexivity and reciprocity in English and Logoori language. This comparison between English, French and Kinshasa Lingala sheds light on what should be considered by teachers, learners and researchers using these three languages.

\section{References}

[1] Gardelle, L.(2012). “'Anaphora', 'Anaphor', and 'Antecedent' in Nominal Anaphora: definitions and theorectical implications" in Cercles pp. 25-40. Lyon: Ecole Normale Supérieur de Lyon.

[2] https://en.m.wikipedia.org/wiki/antecedent_(grammar)

[3] https://en.m.wikipedia.org/wiki/ergative_verb

[4] https://en.m.wikipedia.org/wiki/reflexivity(grammar)

[5] https://en.oxforddictionaries.com/definition/reflexive
[6] https://français.lingolia.com/fr/grammaire/lespronomsreflechis

[7] https://www.gingersoftware.com/content/grammar_rules/recip rocalpronouns

[8] https://www.grammarly.com/blog/reflexivepronouns

[9] O'Grady, W. (2013). Reflexive pronouns in Second Language Acquisition in the Japanese Second Language Acquisition. Monoa: University of Hawai'I at Monoa.

[10] Reinhart, T. An E. Reuland. (2002). Reflexivity. Zie Voor Verantwoording: Bron.

[11] Storoshenko, D. R. et al. (2008). "Reflexivity in English: STAG Annalysis" in Proceeding on the ninth International worshop on Tree adjoin Grammar and Related formalism. Tübigen: Germany.

[12] Richards, Jack C. \& Richard Schmidt (2010). Longman Dictionary of Language Teaching \& Applied Linguistics. Fourth Edition. Longman: Great Britain.

[13] Ducarpe, D. (2018). 32 Reflexive pronoun Examples in Professional writing. Online.

[14] Gluckman, J. (2018). Reflexivity and Reciprocity in Competition in Logoori. Kansas: University of Kansas.

[15] Dunker, D. (2018). The Reflexivity of Language and Linguistic Inquiry. Integrational Linguistics in Practice. First Edition. London: Routledge.

[16] Ejomafuvwe, C. And A. Okenrentie. (2018). "The Reflexive verb in the Grammar of Ufhobo Language" in International Journal of Literature, Language and Linguistics. Vol. 4 (2), pp 187-194, August 2018. Delta State: Delta State University. 